I think that the second and third children were inclosed in the same membranes, though their cords were each attached to its respective lobe of the larger placenta. There was but little hemorrhage, and the womb contracted well after the expulsion of the placentas.

Since the occurrence of the above case, I have attended three other women in confinement, two of whom had twins ; neither of which cases possessed any particular interest.-The Stethoscope.

\title{
OBSTRUCTION AND PERFORATION OF THE BOWELS.
}

[Communicated for the Boston Medical and Surgical Journal.]

As "when sorrows come, they come not single spies, but in battalions ;" so when the young physician's ill luck comes, it comes not singly, but in groups. Very recently, it was my fortune to report the fatal termination of a case of parturition, complicated with a sanguineous tumor of the labia. I have now to report another fatal case, to me quite as novel and interesting.

Thursday evening, Nov. 9, I was called to see Joseph Legg, æt. 10, of slender constitution. He had been sick three days, but had had no medical treatment. Upon examination, I found a hard tumor, three by four inches in extent, in the right iliac region, near the ileo-cœcal union. This was quite tender to the touch. No tenderness of the bowels except in this region. Bowels regular, tongue slightly coated, pulse 110. On close examination I could detect no difficulty except at the point above referred to. Gave sub. mur. hyd., grs. v.; ol. ric., 3 ss.

Friday, Nov. 10th, I found the cathartic had acted, producing a copious watery evacuation, with but little fecal matter. The tumor still existed and was somewhat painful. Ol. ricini was again given, and pulv. Dov. to relieve the pain.

Saturday, 11 th. -1 found the oil had produced free fæcal evacuations, but no diminution in the size of the tumor. Laxatives and anodynes were ordered.

Sunday my patient was more comfortable. Bowels open, tongue cleaning, pulse less than 100, and the tumor less tender and painful. Laxatives and anodynes were continued in diminished doses.

Sunday evening I was called in haste to see the boy. Found him greatly prostrated ; extremities cold ; cold perspiration on face ; respiration hurried; pulse 120, and almost imperceptible ; delirious ; constantly spitting up a frothy substance, with clots of blood; deglutition very difficult; abdomen somewhat swollen and tender, especially over the tumor, and everything indicating a speedy dissolution. Was told that he had, an hour previously, vomited a large amount-a pint at least-of black bloody matter, of a fæcal odor and appearance. Perforation was suspected; and as death was hourly looked for, but little save palliatives was given.

To my surprise I found that my patient was living on Monday, and that he had rallied a little from the prostration of the previous evening. Symptoms of general peritoneal inflammation began to appear. Gave 
pulv. ip. comp. and sub. mur. hyd. in small doses. Injections occasionally, and oil when it could be retained.

Tuesday, Nov. 14th.-Met Dr. Smith, of Chepachet (at whose suggestion I report the case). Found the patient more comfortable. Had rallied from the prostration of Sunday night. General peritoneal inflammation of a severe type, however, was present. Emp. vesicans was applied over the region of the tumor; the anodyne and alterative continued; enemata frequently used, and castor oil given when it could be retained by the stomach. As these (the enemata and oil) afforded no relief, but rather aggravated the symptoms, they were omitted and the patient confined to opiates, alteratives and counter-irritants.

He remained much the same till Wednesday, Nov. 22d. During these eight days, the bowels were very much swollen, the whole abdomen exceedingly tender, the right lumbar, right iliac, hypogastric and left iliac regions being dull, the left iliac and umbilical resonant. Nausea and retching were constant; blood and stercoraceous matter occasionally vomited. He had no evacuation of the bowels from Sunday, Nov. 12th, till IVednesday, Nov. 22d. On the latter day he had a dejection, and another in the night, which greatly relieved him. Laxatives and anodynes in amount sufficient to keep the bowels open and control the pain, were now given, under the use of which he seemed to improve for five days. Swelling of the bowels mostly passed off, but the turnor in right iliac region remained, and was the seat of the most intense pain just before and during defecation. His stools now became more frequent and dark colored, very fetid, and mixed with blood and pus, always preceded and attended by the most excruciating pain in the right iliac and hypogastric regions. They continued to grow more and more frequent, more purulent and fetid, and his strength gradually to fail, till December 12 th, when he died. The tumor in the right iliac region had entirely disappeared before death.

1 have purposely omitted further particulars in the history of the symptoms and treatment, as they would unduly prolong these notes without adding to the interest of the case, since my chief object is to report the appearances levealed by a post-mortem examination.

Autopsy_eight hours after death. Present, Drs. Smith of Chepachet, and Wever of Paseoag, with several residents of the place. Nothing peculiar in external appearance. Abdomen only examined. On opening the cavity, found evidences of general peritoneal inflammation. Strong adhesions and small purulent deposits throughout the whole cavity. Adhesions of the intestines so firm as to require the scalpel to separate them. Firm adhesions between the bowels and abdominal walls commenced two inches above the crest of the ileum, extending to the median line, down to the brim of the pelvis, across the hypogastric region, and involved a part of the left iliac. On dissecting up the abdominal parietes, six inches of the ileum, the cœecum, lower half of the ascending colon, and sigmoid flexure, seemed to form a single inseparable mass, confined by continuous adventitious bands and membrane. In dissecting near the ileo-coecal communication, to separate the mass, a cavity was cut into containing a small amount of pus and 
fæcal matter. In exploring this, it was found to communicate with other smaller ones, extending over the right iliac and hypogastric regions, also that it made its way above into the ileum, two inches from the ileo-caecal valve, and extended down into the cavity of the pelvis, where it perforated the coats of the rectum, through which its contents had been discharged. Through this cavity a direct communication existed between the ileum and rectum. There was complete occlusion of the ileo-cœcal communication, and the cœcum was so collapsed and contracted that it had no appearance of ever having been a coecum. Aside from this locality, the abdominal viscera presented no appearances not usually met with in ordinary cases of peritoneal inflammation.

Pascoag, R. I., Dec. 22, 1854. S. O. GRIFfin, M.D.

\section{AN EXTRACT FROM HEISTER.}

[Communicated for the Boston Medical and Surgical Journal.]

Messns. Editors, - As a relic of the medical literature of a century ago, perhaps the following extract from the Introduction to "Heister's Institutions of Surgery," printed in London in 1753, may not be uninteresting to your readers. Medical students, of the present day, seldom read the oider authors. Yet these are not wholly unworthy their attention. For, with much that is useless, they contain a vast deal that is truly valuable. To preserve from threatened oblivion the better portions of the writings of the fathers in medicine, is a worthy deed.
Bristol, Ct., Dec. 15, 1854.
A. M. Hooker.

\section{EXTRACT.}

Having already described the principal Instruments as well as Medicines, with which a Surgeon must of necessity be provided, it remains to examine into the qualifications that he ought to be master of, to render him useful in his Profession. The Agility of Body, and Resolution of Mind that are necessary to a surgeon, are elegantly described by Celsus : "A surgeon [says he] ought to be in his full vigour, to have a strong, steady Hand, never given to tremble, and to be as ready with his Left Hand as his Right, to have a quick, clear Sight, an intrepid Mind, void of all Tenderness, so as not to be at all mored by the Outcries of his Patient ; to use no more Haste than the Case requires, nor to cut less than is necessary ; but he should act in all respects as if he was entirely unaffected by his Patient's Complaints." But at the same time, I woukd have him behave with such Caution as to be guilty of no Act of Rashness or Cruelty, and very carefully avoid giving unnecessary Pain.

The two Qualifications that I have just recited, are by no means sufficient of themselves to render the Surgeon perfect; but there are others also which Celsus has passed over, which are highly useful and necessary. No one will excel in Surgery unless he is first furnished with a good natural Genius, to which he must join a well-grounded Knowledge in Anatomy and Medicine; if he is furnished with these Gifts, 